\title{
The Daredevils of Sassoun: The Deep Structure of the Plot
}

\section{Suren Zolyan*}

\begin{abstract}
The plot can be considered as the content, as well as the pattern of semantic organization of the text. In this regard we suggest making a distinction between deep and surface levels of the plot. In respect to the Armenian epic The Daredevils of Sassoun this distinction provides real opportunity to reveal the integrity and coherence of the epic viewed as a unified set of all of its various branches, versions, episodes and even variants, - despite that, on the surface level, the cohesion between and within the various branches of the epic is rather weak. The underlying semantic structure is based on two associated axes (patrilineage - matrilineage; patrilocality - matrilocality) and two fundamental oppositions (masculine - feminine; own - alien). The deep plot of the epic can be understood as a representation of the transition from the matrilineal (matrilocal) system in its radical form (denying men's role in childbirth) to the opposing radical patrilineal system denying women's role in its absolute and, therefore, tragic form (denying continuation of life). The well-known Lévi-Straussian quasi-algebraic formula of the semantics of myth can be used as an instrument for examining a formal representation of this plot.
\end{abstract}

Key words: Armenian epic, Daredevils of Sassoun, epic as multisemantic and multidimensional set of semantic varieties, deep and surfaces structures of the plot, LéviStraussian formula and its application for epic.

0. The Armenian heroic epic The Daredevils of Sassoun is an outstanding poetic work which is reasonably associated with the very spirit of the Armenian people and its historical destiny. On 5 Dec 2012 the epic poem The Daredevils of Sassoun was included on the UNESCO Intangible Cultural Heritage list. Despite the fact that it was recorded in a relatively late period, ${ }^{1}$

\footnotetext{
* Author's address: Suren Zolyan, National Academy of Sciences of the Republic of Armenia, Institute of Philosophy and Law, Yerevan 0010, Republic of Armenia, 44 Aram Str. E-mail address: surenzolyan@gmail.com.

1 The epic was orally transmitted over the centuries (approximately from IX century), and it was only recorded for the first time in 1873 by Bishop G. Srvandzatyan. However, there were some earliest references to the epic made by the Portuguese traveller Mestre Afonso (XVI century) and the Kurdish historian Sharaf Khan Bitlis (XVI century) - see Harutiynyan 1977: 619-620; 626-628.
} 
immediately after its recognition the poem had a great impact on the Armenian mind, literature and ideological patterns. The main heroes of the epic, especially the central hero - David of Sassoun -, are considered as everlasting symbols of Armenian identity. Even during the latest presidential elections one of the candidates used this epic as a political platform for his presidency. However, the curiosity of that fact reflects the highest degree of embodiment of these heroes even within the everyday ideological patterning of modern Armenia.

1. Such a close connection between the epic poem and the current state of affairs demonstrates the obvious impact it has on perception. Like the legend of Hayk, the poem is considered mainly from patriotic stance - as a victorious fight of the Armenian people against foreign invaders for independence, identity, religion, and the very existence. On the other hand, the traditional philological approach is concentrated on revealing the manifestation of historical data in the poem: of course, having some historical facts as grounds, the poem transformed these facts in to narrative or poetic folklore patterns. The third direction is the comparative etymological analysis of the poem, which is oriented towards the explication of the mythological genesis of main characters.

2. However, the epic is worthy enough to be studied for itself - not as a sometimes incomplete and controversial reflection of other systems (historical or mythological), but as a coherent, comprehensive and consistent self-sufficient semantic system. Paradoxically, there have been very few attempts to study this poem as it is - first of all, as a poem and a text, which should be studied by the methodological means of poetics and text-linguistics. To some extent this lacuna was examined by Azat Eghiazaryan (Eghiazaryan 1999; 2009; see also: Bardakchyan 2011, Lint 2011). We, too, will focus on the poetics of the poem, but, in comparison with A. Eghiazaryan, our study intends to represent the structural aspects of the poem and its inner semantics. The application of modern conceptions and methods of text-linguistics and semiotics of text allows us to identify the structural consistency of the poem and to view it from a new perspective. This approach will thus aim to reveal the deep formal semantics of the poem.

3. However, there is a serious obstacle which comes to question - are the methods of text-analysis applicable to the epic poem? And, if they are, to what extent and how? As a matter of fact, there is no complete text of The 
Daredevils of Sassoun ${ }^{2}$ - usually, such function is performed through the composite text compiled in 1939 by the prominent scholar of Armenian folklore and literature Manuk Abeghyan with the assistance of Gevork Abov and Aram Ganalanyan. Of course, he completed his work by combining different versions and episodes within a consistent fabula in the best way he could manage. But in any case, it is a philological reconstruction, not the original story. On the one hand, one cannot find any version that includes all four branches, as it was represented only in Abeghyan's composite text. On the other hand, there are many very interesting episodes and details that were excluded from it. However, we do not intend to evaluate the work as perfectly accomplished by $M$. Abeghyan and his colleagues - up to date it remains unchallenged. Our main objective is to study all existing versions and to reveal the inner organization of different variants and the deeper semantic cohesion even between non-connected versions and episodes.

4. First of all, such an approach presupposes a new way for considering text and the mechanisms of its structuring and functioning. We have to abandon the traditional mode for treating text as a linear concatenation of episodes interconnected through causal and temporal interrelations. For us, one should distinguish text as a ready product and text as a generative model for creating such products. The usual literary works create the illusion that there is that complete and final version, which is the text itself, and all the other versions are non-perfect attempts in the process of drafting the last and best version. However, such an approach is not applicable to folklore text, especially to mythology. So it was myth that was used for introducing a new way of textanalysis. In his pioneer work, “The structural study of myth", Lévi-Strauss

2 There are about 160 versions and episodes which were recorded and published in the 19th and 20th centuries. A scholarly edition of the collection of different versions was published as a four-volume work in five parts (vol. i, 1936; vol. ii, part 1, 1944 and part 2, 1951; vol. iii, 1979; and vol. iv, 1999, all in Yerevan, Publishing House of the Academy of Sciences of Armenia). Even at the very beginning of recording this poem, there were serious difficulties to find narrators who knew a more or less complete story. As Bishop G. Srvandzatyan mentioned in preface to the first publication (1873):

For three years I tried to find somebody who knew the entire story, but nobody seemed to know all of it until I met Gurbo from a village on the Moush plain. I learned that his master had two pupils who also knew the tale by heart, singing verses in it, although Gurbo himself had not recited it for so long that he had forgotten a good deal of it. Nevertheless, I kept him with me for three days, I begged him, cajoled him, honored him, rewarded him, and when he felt better and was in the proper mood, he recited the tale for me in his own village dialect, and I wrote it all down in his own words. 
suggests to consider myth as multidimensional structure, like a musical text, ${ }^{3}$ where the linearity of the speech is overcome by semantic and structural means. On the semantic level text can be considered as a model for creation of different compositions and it should be interpreted as a set of interconnected possible worlds. In the case of the epic The Daredevils of Sassoun it is possible to describe some configurations of relations, structures and meanings which can be considered as a deep template for certain semantic models. The semantic model is a set of basic semantic objects, events and relationships which are reproduced in different ways in various branches, versions and episodes. The variations and transformations of the same semantic model appears as a manifestation of the same deep structure in the text of epic poem, where epic is understood as an ordered set of all semantic variants.

5. Now, after recent development of text-linguistics and modal semantics it is possible to give solid linguistic grounds for the Lévi-Straussian ideas about myth as a multidimensional non-linear structure (and even more, his idea that myth is considered an instrument for overcoming the linearity of time). In our previous publications (Zolyan 1991; 2012; 2013) we tried to describe the inner formal structure of the text from the same viewpoint. In brief: when referring to the semantics of text, its substantial distinction from the semantics of other units should be taken into consideration. Unlike an utterance, text does not have fixed pragmasemantics, i.e. its dependence on a certain communicative context. Herewith, text is liable to semantization assuming a correlation with the other domains of reference (possible worlds). It presupposes the description of text as relations (functions or correlation mechanism) correlating a set of possible worlds (some state of affairs) with a set of possible contexts, whereby such worlds and contexts in which the value of constituent utterances acquires the value of "true". Text thus acts as a peculiar analogy of the concept of a model and of model structure in modal logic (Kripke 1963); that is, it is a procedure of correlating propositions and possible worlds within this or that model structure formed by the text itself, as well as within the correlation of contexts where the text is actualized. It is noteworthy though, that Leo Tolstoy approached the idea closely and expressed it through a fine metaphor (about his novel Anna Karenina): "endless labyrinth of linkages" (Tolstoy 1876). Text value is chiefly polysemantic, and the metaphor comes to elucidate that the novel semantics cannot be reduced to even a very complex linear structure. Instead it should be understood as an infinite set of possible

\footnotetext{
3 "The myth will be treated as would be an orchestra score perversely presented as a unilinear
} series and where our task is to re-establish the correct disposition" (Lévi-Strauss 1955: 432). 
interpretations - transworld relations. Such an approach has been replacing the traditional notion of text, which defines text as a verbal composition, isolated from the other compositions through definite and easily recognized boundaries (beginning - end of the text)

6. From this point of view, in the case of The Daredevils of Sassoun the set of possible interpretations is given, but not as a different reader's responses - this set is formed by the different versions of the main semantic template. So, it does not matter whether there is such a thing as a final version of the text, but the main issue is - to what degree it is possible to consider all the versions as transformations of the same underlying structure. Are the textual worlds of different versions compatible with each other, and what types of semantic relations are set up between them? The consistency should be established both within the textual structures and between them, taking into account the paradigmatic cohesion between different versions of the poem. From such a theoretical stance the epic The Daredevils of Sassoun can be considered a proper instance of text, which has not been reduced to any one of its occasional manifestations (composition of branches. episodes, stances, etc.), but, let's repeat, as an "endless labyrinth of linkages". However, such linkages are not chaotic and voluntary, and have their inherent logic that maintains the construction as a whole.

7. Two approaches to a plot are possible: one addresses a plot as an ideology, and the other, as a form of text organization. The first is visible to both the author and the reader, while the second is not obvious and can only be uncovered through meta-textual analysis. It is not so much content but the semantic form that organizes content as such. This situation calls for a linguistic analogy: these aspects of semantics (content vs semantic form of content) appear as its surface vs. deep levels (structures). The surface level of the plot is more ideological by its nature, it is what the reader is able to perceive immediately. The deep structure of the plot is a semantic frame or formal structure for bonding and organizing varieties of events and characters on the surface level. The deep level is unconscious and can be described only through meta-textual procedures. On this level meaning that can be assigned to the text appears to be invariant resulting from the surface transformations. This does not mean that the deep level expresses a deeper content; rather, it represents an invariant that is reflected at the surface level as a result of its reframing and transformation. As it seems, the first time the distinction between deep and surface structures of text (without using such terms) was drawn by Vladimir Propp (1928a/b). In post-folklore literature invariant deep structures are characteristic features of the genre rather than individual texts, while in folklore, they are, as a rule, 
textual semantic structures inherited from the previous stage and organized as a semantic pattern of plot. As V. Propp showed later (1959), it is especially evident at the stage of the transition from Myth to Epic, when the semantic systems of the previous stage turn out to be a form for expressing other content and mind, while retaining the system of previous oppositions.

8. This distinction between deep and surface structures has very interesting consequences for the epic - it shows rather strong degree of textual cohesion and coherence on the deep level regardless of a relatively low degree of coherence on the surface level. When applied to David of Sassoun, this distinction makes it possible to see the integrity and coherence of the epic viewed as a unified set of all its various branches, versions, episodes, and even variants of the same episodes. Thus, on the surface level, the cohesion between various branches (cycles) of the epic is rather weak and is maintained exclusively by the genealogy of the main characters (the character of the following branch is a son of the character of the previous branch), as well as due to the fact that all the events are connected with the same central locus (Sassoun). Inside the branches, the plot also is divided into a number of poorly interconnected episodes, which can be arranged and re-arranged rather freely; furthermore, significant variations and differences are evident between the existing versions of the epic. At the same time, the deep level shows exclusive integrity and cohesion, not only between the branches, but also between various fragments and variants of the epic. The factor holding it together as a sort of a carcass is the semantic pattern reflecting the structure of the archaic society and its transformations. This pattern is based on two associated, but not always coinciding, axes (patrilineage - matrilineage; patrilocality - matrilocality) and two fundamental oppositions (masculine - feminine; own - alien).

9. From this point of view diversity of the numerous versions is a great advantage for the aforementioned approach. The relatively late time of recorded epic provides an additional opportunity for emerging new variants. In the course of its functioning exclusively in the oral form, the text has permanently been subject to significant changes. The absence of fixation caused free variations of the basic thematic structures. Various versions represent the possibilities of different developments of the same semantic structure. So, instead of the non-existing "original" text or the "true" version, there is a paradigm of the mutually interchangeable and complementary variants. Syntagmatic connectivity of the plot is complicated and enriched by its paradigmatic dimension. For instance: there is no constant kinship between main hero David and his antagonist Msra Melik. In different versions Msra Melik appears as David’s 
step-father, step-uncle, step-brother, or as the son of the step-mother of David and even as a bastard ( $2 \mathrm{n}\left\llcorner\left\{\mathrm{i} \mathrm{k}_{\mathrm{i}} \mathrm{h} \mathrm{h}\right.\right.$, shun Melik') - son of the lover of the second (young) wife of Mher the Lion (=David's step-mother). However, we can reveal the main pattern (Msra Melik is David's step-father or elder step-brother) and its various transformations. These transformations do not change the main invariant features, i.e. Msra Melik's affiliation to the clan and locus of the matrilocal (second) wife of David's father (Mher the Lion). On the surface level, only one of the possible relations can be chosen, i.e. either that of a step-father or step-brother, step-uncle, etc. But on a deep level, all the relations are possible should they meet the invariant features. So the same set of semantic entities is relevant on both levels - but on the deep level there is a conjunction of features and disjunction that takes place on the surface level. The other semantic features (first of all, ideological) can be combined with this deep invariant. Ideological features should justify the inner alien relations between patrilocal Sassoun and matrilocal Msir, and this unsolved controversy on the observable surface level is interpreted as a patriotic or religious fight of Armenian Christians against foreign conquerors and/or idolaters. However, there are some "non-patriotic" versions (f.e., narrated by Arakel Shakoyan from Nor Bayazet) - after his victory David left Sassoun and moved to Msir as a legitimate $\mathrm{king}^{4}$. So the ancient Oedipus's pattern of obtaining power has still

4 The same pattern of obtaining power is also presented in "ultra-patriotic" variant, but in this case David has rejected such option:

Utip luuup. Чnnnh,

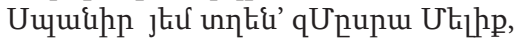

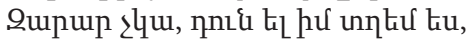

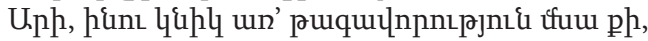

Uunpi h puquunnnıpjnı\& upu,

Uuunta qupp pniq h:

Tulhp l'uuh.

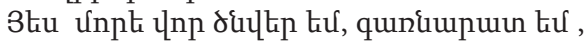

$<$ quind uilumuins $>$

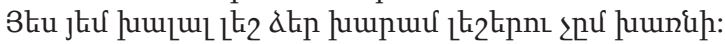

(Mer kasi. Vordi, Spanir yem tghen' zMysra Melik', Zarar ch'ka, dun yel im tghem yes, Ari, inu knik arr' t'agavorut'yun mna k'i, Msyrn el t'agavorut'yun ara, Sasun zat'i k'vonn i: Davit' k'asi. Yes more vor tsnver yem, garrnarat yem, <garrn anarat> Yes yem khalal lesh dzer kharam lesheru chym kharrni:) - The mother [of Msra-Melik] says, "My son, you have killed my son MsraMelik, No matter, you are also my son. Let's take his wife and will get Msra-Melik's kingdom to you, as Sassoon already is yours." David answers, "Since I was born from my mother I have been sinless (innocent) lamb, And I do not mix my pure (khalal) flesh with your dirty (kharam) fleshes (narrator Mktrtich Harutunyan from Shatakh)." Paradoxically the narrator uses both the Islamic (Khalal - Kharam) and Christian (sinless lamb) terms for designating purity and unputity. 
prevailed in this case. Such cases are exemptions from the surface ideological level, but they are in line with general logic of the deep plot.

10. The scene of fight between David and Msra Melik is just an example for drawing distinctions between deep and surface semantic levels and functions of the same semantic elements within the different interpretative frameworks. It demonstrates that for the explanation of the isolated episode a general system should be constructed, and only within such framework all the components will obtain their meanings and functions. The semantic organization of The Daredevils of Sassoun is similar to the main principles of myth, which were described by Lévi-Strauss as follows:

1. If there is meaning to be found in mythology, this cannot reside in the isolated elements which enter into the composition of a myth, but only in the way those elements are combined....

3. Those properties are only to be found above the ordinary linguistic level; that is, they exhibit more complex features beside those which are to be found in any kind of linguistic expression" (Lévi-Strauss 1955: 430, 431).

At the same time, Lévi-Strauss suggested there is a universal pattern of the mythological plot - it is a way of resolution of irresolvable contradictions. Using the linguistic technique of structural analysis, Lévi-Strauss describes the dynamics of events as consequences of binary oppositions. It is due to them that the initial irresolvable semantic opposition still remains, but in a softer form - controversial, but not contradictory. The process of bringing together the most fundamental oppositions is mediation - finding the common ground within the binary oppositions and transition to the new pairs of less radical opposition. As a final step, the semantics and structure of the last opposition is something like a mirror's reflection of the initial pair. According to LéviStrauss, this process determines the underlying structure of any myth, and it can be modeled by quasi-algebraic means:

Finally, when we have succeeded in organizing a whole series of variants in a kind of permutation group, we are in a position to formulate the law of that group. It seems that every myth (considered as the collection of all its variants) corresponds to a formula of the following type:

$$
\operatorname{Fx}(\mathrm{a}): \mathrm{Fy}(\mathrm{b})=\mathrm{Fx}(\mathrm{b}): \mathrm{Fa}-1(\mathrm{y})
$$

Where two terms being given as well as two functions of these terms, it is stated that a relation of equivalences still exists between two situations, when terms and relations are inverted, under two conditions: i.e. 1 . that one term be replaced by its 
contrary; 2 . that an inversion be made between the function and the term value of two elements (Lévi-Strauss 1955: 441, 442).

11. Of course, this formula should be used only as a carcass, or as a guideline which shows the direction of semantic operations. However, there is an astonishing correspondence between this Lévi-Straussian formula and the structural organization of The Daredevils of Sassoun epic's content. Maybe, Vladimir Propp's theory can explain such strong correlation between deep semantics of The Daredevils of Sassoun and Lévi-Strauss formula: that is how the transition from myth to epic transforms the content system of myth, - meanwhile the system of semantic oppositions and categories which is inherited from the previous stage remains unchangeable and has been becoming a formal means of expression for the new content and new ideological patterns. As it was shown in the aforementioned example, the opposition "matrilocality vs patrilocality" ceased to be realized for narrators and theirs audience, but it still remains actual as a structural bond for the new surface semantic oppositions:

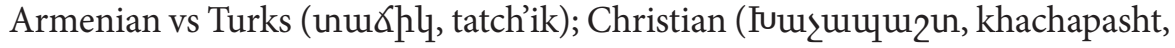
literally - worshipper of Cross) vs Idolater (lnuwuuzun, krapasht; literally worshipper of idol).

12. When we consider the correspondences between the epic and the LéviStraussian formula, first of all, there is obvious compliance between the number of terms within the formula and the number of branches: it is an exceptional case, when the epic describes the activities of four generations, when in the other cases a maximum three generations are present (Nekludov 2011). Then, there is an ordered group of semantic oppositions which determine the gradual transition from the initial situation to its inversed form at the finality of the epic. The main pattern which has regulated the whole structure of the epic can be represented by the Lévi-Straussian formula $\operatorname{Fx}(\mathrm{a}): \mathrm{Fy}(\mathrm{b})=\mathrm{Fx}(\mathrm{b}): \mathrm{Fa}-1(\mathrm{y})$, which is semantically interpreted in the following way:

$$
\begin{aligned}
& \text { a: - + women; (feminine) } \\
& \text { b: - + man (masculine) } \\
& \text { Fx: + childbirth } \\
& \text { Fy: absence of childbirth } \\
& \text { Fa-1: absence of women }
\end{aligned}
$$


The semantic matrix of the first branch can be described as:

$$
\begin{array}{ll}
\mid+ \text { woman } \mid & \mid \text { man } \mid \\
\mid+ \text { childbirth } \mid & \text { VS }
\end{array}
$$

It is formal representation of the matrilineal (matrilocal) system in its radical form (denial of men's role in childbirth; progenetress Tsovinar's conception from water, her leaving husband's home and return to father's home; killing of the father by the sons; the emerging of Sassoun house).

The matrix of the fourth branch can be represented as the mirror inversion of the first ${ }^{5}$ :

$$
\begin{array}{ll}
+ \text { childbirth } \mid & \mid \text { absence of women } \mid \\
+ \text { masculine } & \text { VS }
\end{array}
$$

(Mher's sterility and his capture in the cave; father's condemnation - symbolic killing of his son ${ }^{6}$, Mher's killing (sometimes unmotivated) of women, the delivery of Mher's wife Gohar's dead body from her home to Sassoun ${ }^{7}$; the end

5 As it was shown by James Russell, there is strong mirror symmetry and inversion between initial and final episodes even on the surface level, and it is also represented by the timing: The timing of the ending of the episode of Pokr Mher is itself of a great interest in resolving the issue of the integrity of the epic as a single work. The action of epic opens on Ascension day, when the maiden Tsovinar goes out for a last walk on the shores of the lake Van before being send away to Baghdad in marriage the Arab caliph. She is thirsty and drinks one-andhalf handfuls of a milky liquid that gushes from a phallic rock. Nine months later the unequal twins, Sanasar and Baghdasar, are born: the former founds the fortress Sassoun. At the end, Mher is immured in his cave, which opens on the eve of Ascension day... The action of the epic can thus be seen as taking place within the cycle of an archaic ring composition; and this is a strong argument for its narrative integrity as something much more intricate than a collection of different legends (Russell, forthcoming; see also: Russell 2007).

6 In some version Mher cowardly killed his son Hovhanes (narrator - Sargis Hakopyan from Kavar) Certainly, this episode is against the general line of the surface plot (Mher's father David condemns his son Mher to be childless and immortal), but it completes the main deep scheme of the epic - the killing of father by his step son (initial situation) is replaced by killing of prodigal son by his biological father.

7 <Uhtip > qiuug, Unuul hp unnte,

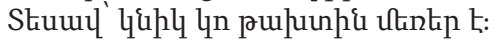

2tin tunn liquuí ďtin, 


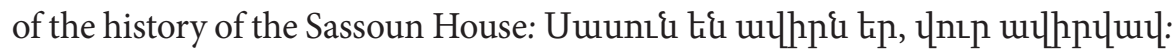
(Sasun yen avirn yer, vur avirvav: - Sasun was ruined and ruined - completely).

It is the opposition to the first matrix the radical patrilineal and patrilocal system in its absolute, and, therefore, tragic form: denying women's roles imply the ceasing of life. Thus the semantic structure of the epic can be described as a gradual transition from the initial matrix of the first branch to its opposite mirror inversion, and that rather strongly correlates with abovementioned logics of mythological plot.

The end of the epic - the imprisonment of sterile Mher in the cave - can be considered a meditative form of a mythological thinking opposition:

(LIFE vs DEATH) vs IM-MORTALITY

The absence of death in association with the absence of offspring (that is, life) is the negation of both members of the opposition. Thus, the incompatible members of opposition, life and death, are aligned in their inverted form. The absence of death is paired with the lack of offspring, and the presence of offspring - with death ${ }^{9}$. It is easy to see that this opposition is a deep structure also for the above-mentioned semantic formula of epic, and, in its turn, this formula is its meta-manifestation.

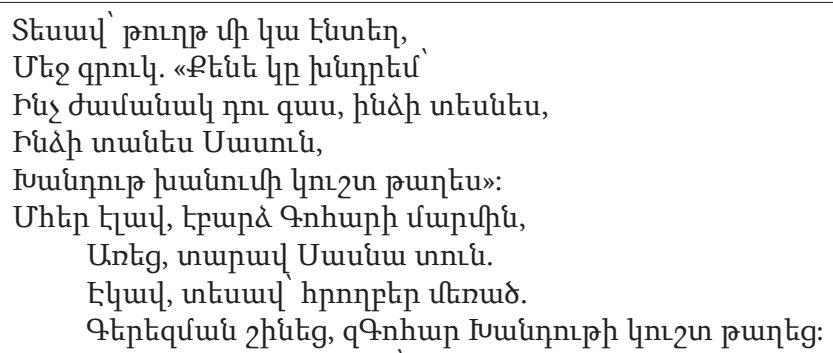

$<$ Mher> Gnats', mtav ir tun, Tesav ' knik ko t'akhtin merrer e: Dzerr etu knkan dzerr, Tesav' t'ught' mi ka entegh, Mej gruk. «K'yene ky khndrem 'Inch' zhamanak du gas, indzi tesnes, Indzi tanes Sasun, Khandut' khanumi kusht t'aghes»: Mher elav, ebardz Gohari marmin, Arrets', tarav Sasna tun... Gerezman shinets', zGohar Khandut'i kusht t'aghets' $-<$ Mher $>$ went into his house and saw that his wife who was lying on the couch had died. Mher took her hand and saw the paper, where it was written: "I beg you - whenever you shall come to see me Gohar. Take me to the Sassoon and bury near Khandut Khanum. Mher took Gohar's body and set out for Sassoun... He dug a grave next to Khandut tomb, there inherited."

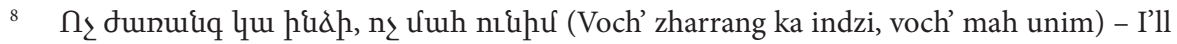
have neither heir nor shall I have death.

9 hư ghig hư ưùhg t,

Łn hư uŁpứ Łn, np hidąh uuwuitig (Im ts'yets' im andzits' e, Ed im sermn er, vor indzi spanets') - My moth is from my very own body. It is my very own seed that killed me. 


\section{References}

Bardakjian, Kevork B. 2011. Daredevils of Sasun: Poetics of an Epic, by Azat Yeghiazaryan, trans. S Peter Cowe. In: Middle Eastern Literatures 14, 3, 324-327.

Eghiazaryan, Azat 2008. Daredevils of Sasun: Poetics of an Epic, trans. S. Peter Cowe. Costa Mesa, CA: Mazda Publishers.

Harut'yunyan, Sargis 1977. Hay zhoghovrdakan vepy [Uupqhu Zupntpjnı\{juid:

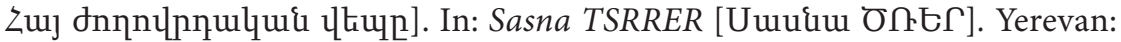
Sovetakan grogh, 619-642.

Kripke, Saul 1963. Semantical Analysis of Modal Logic I. Normal Modal Propositional Calculi. In: Zeitschrift für Mathematische Logik und Grundlagen der Mathematik 9, 67-96.

Lévi-Strauss, Claude 1955. The Structural Study of Myth. In: The Journal of American Folklore 68, 270, 428-444.

Lint, van Theo M. 2010. Review: Daredevils of Sasun: Poetics of an Epic, by Azat Yeghiazaryan, trans. S Peter Cowe. In: Comparative Literature Studies 47, 4, 558-561.

Nekljudov, Sergej 2003. Tipologija i istorija v pamjatnikakh geroicheskogo eposa. In: The Armenian Epic "Daredevils of Sassoun" and the World Epic Heritage. 4-6 November, 2004 [=2003] Tsakhkadzor. Yerevan: National Academy of Sciences of Armenia, 17-24.

Propp, Vladimir 1928. Transformacii volshebnykh skazok. In: Poetika IV. Leningrad: Academia, 70-89.

Propp, Vladimir 1928. Morfologija skazki. Leningrad: Academia.

Propp, Vladimir 1958. Russkij geroicheskij epos. Moskva: GIHL.

Russell, James 2007. The shrine beneath the waves. In: RES, Antropology and Aesthetics 51. Cambridge, MA, 136-156.

Russell, James (forthcoming). Mithra in the epic of Sasun: Armenian Apocalypse. In: Proceedings of the conference on Armenian Apocalyptic. Jerusalem: Hebrew University of Jerusalem.

Tolstoj, Lev 1984. Pis'mo L. N. Tolstogo k N. N. Strakhovu (Jasnaja Poljana, 1876, aprel', 23 i 26). In: Tolstoj, Lev. Sobranie sochinenij v 22 t., t. 18. Moskva: Hudozhestvennaja literatura, 784-785.

Zolyan, Suren 1991. Semantika i struktura poeticheskogo teksta. Erevan: Izdatel'stvo Erevanskogo universiteta. 
Zolyan, Suren 2012. Text as a multisemantic entity - a prolegomenon to formalization. In: International Congress Cultural Polyglotism To the anniversary of Juri Lotman's 90-th birthday Tartu, February 28 - March 2, 2012. Abstracts. Tartu: University Press, 57-62.

Zolyan, Suren 2013. Tekst kak mul'tisemanticheskij ob’ekt. In: Čuždoezikovo obučenie XL, 2 (Foreign Language Teaching 40, 2), 145-172. 